\title{
Efeito do Cermet na manutenção do esmalte sem apoio de dentina em restaurações de amálgama
}

\author{
Angelo Stefano Secco* \\ Ewerton Nocchi Conceiçáo** \\ Léo Werner Suffert***
}

\begin{abstract}
RESUMO
Este estudo avaliou o efeito do CERMET na manutenção do esmalte socavado em restauraçōes de amálgama.
\end{abstract}

\section{SUMMARY}

\begin{abstract}
This research evaluated the effect of CERMET in maintenance of dental enamel without dentin suport
\end{abstract} in amalgam restorations.

\section{UNITERMOS}

Manutenção de esmalte, Cimento de ionômero de vidro, amálgama.

\section{Introdução}

Apesar da resina composta ter obtido considerável avanço nos últimos anos, o amálgama de prata, continua ocupando um lugar de destaque quando da restauraçăo de dentes posteriores, representando aproximadamente dois terços das restauraçōes executadas (9). Entretanto, o clínico que utiliza o amálgama vê-se obrigado a remover considerável porção de estrutura dentária hígida, devido às suas propriedades físicas, que requerem um preparo cavitário específico para proporcionar retenção e estabilidade à restauraçāo. Com isso, os dentes tornam-se mais suscetiveis à fratura quando submetidos à forças de compressão como mostram diferentes estudos relacionando o aumento do preparo cavitário com a diminuição da resistência dos dentes $(1,2,14,25,29,30)$.

Com o advento do ataque ácido desenvolvido por BUONOCORE (4) e o surgimento de materiais restauradores adesivos tem sido possível em alguns casos minimizar a quantidade de tecido dentário removido nos preparos cavitários e manter ou mesmo aumentar a resistência dos dentes restaurados $(11,26)$. Contudo, nos dentes posteriores ainda é controvertido o uso de resina composta, pois as suas indicaçōes e limitaçōes ainda não estão bem definidas, e isto tem levado, em muitos casos, a aplicações clínicas inapropriadas (5). O Cimento de lonômero de Vidro tem sido utilizado como material de base para restaurações de resina bem como de amálgama, a partir de técnica sugerida por McClean e col., $1988(21,23)$. Com a introdução do CERMET, ELDERTON, 1991 (8) e MCLEAN, J.W. 1991 (24) sugeriram sua utilização como substituto de dentina, devido a suas propriedades físicas.

Este trabalho tem por objetivo verificar a influência da utilização do cermet na manutenção do esmalte socavado, em restauraçōes de amálgama possibilitando desse modo diminuir a quantidade de tecido hígido a ser removido.

\section{Materiais e Métodos}

Foram utilizados 21 dentes humanos extraídos e mantidos hidratados em água, possuindo dimensões médias segundo GALAN JR. 1970 (10).

Os dentes foram examinados com auxílio de uma lupa estereoscópica (wild) com 25 aumentos e aqueles com trincas e/ou fraturas foram rejeitados.

Então foram confeccionados preparos cavitários tipo $\mathrm{MO}$ deixando-se esmalte socavado de acordo com os seguintes passos:

Abertura da caixa proximal com broca KG SORENSEN $n^{\circ} 3100 \mathrm{em}$ alta velocidade com spray ar água com profundidade de $4.0 \mathrm{~mm}$ e abertura vestíbulo-lingual de $4.0 \mathrm{~mm}$. A seguir, foi realizado o preparo da face oclusal utilizando ponta diamantada KG SORENSEN $n^{\circ} 3100$, na profundidade de $3.0 \mathrm{~mm}$ e dimensão vestíbulo-lingual de $1.2 \mathrm{~mm}$. Removeu-se então a dentina de sustentação do esmalte com broca KG SORENSEN n³050, penetrando-se pe-

\footnotetext{
* Bolsista de iniciaçāo científica (FAPERGS) FO/UFRGS

** Professor Auxiliar de Materiais Dentários FO/UFRGS

*** Professor Titular de Materiais Dentários FO/UFRGS
} 

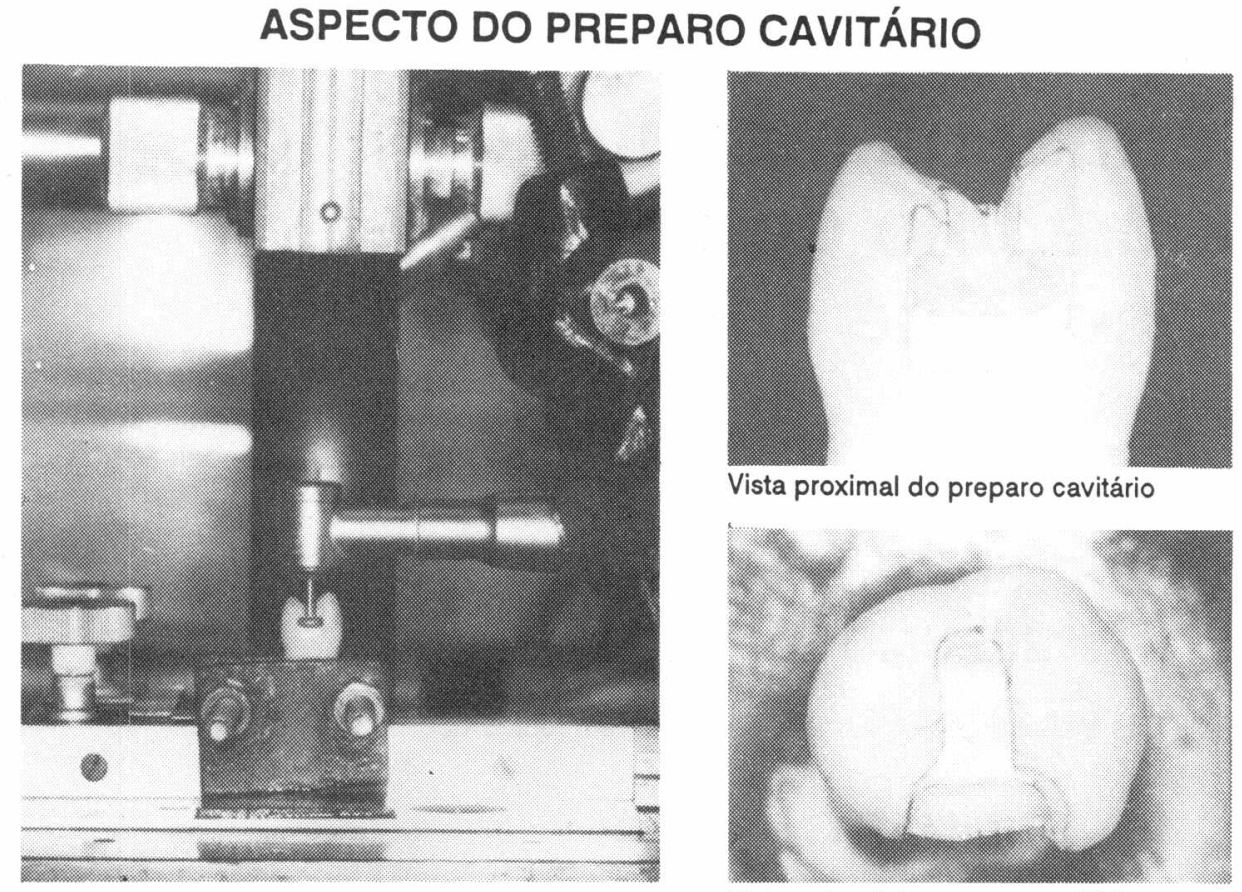

Vista proximal do preparo cavitário

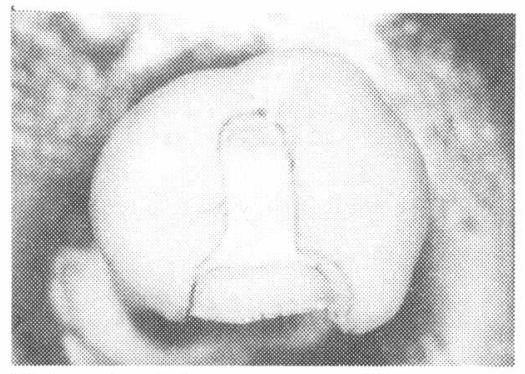

Vista oclusal do preparo cavitário

TABELA 1

Materiais Restauradores Utilizados

\begin{tabular}{lll}
\hline Dentes & Marcas Comerciais & Fabricante \\
\hline Grupo 1 & Não restaurado & - \\
Grupo 2 & Copalex & Inodon \\
& Dispersalloy & Johnson \& Johnson \\
Grupo 3 & Chelon Silver + & ESPE \\
& Copalex & Inodon \\
& Dispersalloy & Johnson \& Johnson \\
\hline
\end{tabular}

la caixa proximal no sentido mesiodistal, na junção amelodentinária (fig. 1). Então os dentes foram incluídos por suas raízes até um milímetro aquém da junção cemento esmalte. Logo após, foram divididos aleatoriamente em 3 grupos de 7 dentes cada, conforme o material restaurador utilizado (tabela 1).

Foi realizada a profilaxia das peças dentárias com taças de borracha e pedra pomes e lavagem em água corrente por um minuto. Para a confecção das restauraçōes, matrizes metálicas foram fixadas a porta matrizes e adaptadas aos dentes preparados. Para restaurar os dentes do grupo 2 inicialmente aplicou-se 0 verniz em duas camadas na cavidade com intervalo de 30 segundos entre as aplicaçōes. Após, realizou-se a trituraçăo mecânica do amálgama com auxílio de um amalgamador Dentomat, por 25 segundos, sendo o material inserido na cavidade conforme técnica de rotina.
Nos dentes do grupo 3 foi realizado o condicionamento da dentina com ácido poliacrílico a $25 \%$ por 15 segundos e lavagem com água corrente por 30 segundos. Após a manipulação do CERMET por 30 segundos e inserção na cavidade com auxílio de uma seringa centrix, forrando esmalte socavado, foi aplicado verniz cavitário e inserido o amálgama com a mesma técnica utilizada para o grupo 2 (fig. 2).

A seguir, os dentes foram armazenados em estufa a $37^{\circ} \mathrm{C}$ com umidade relativa de $100 \%$ por sete dias. Então, os corpos de prova foram submetidos ao carregamento axial de compressão em uma máquina de ensaio universal (Losenhausenwerk), com capacidade de $2000 \mathrm{~kg}$ com velocidade de $0,5 \mathrm{~mm} / \mathrm{min}$. Uma esfera de aço de $4 \mathrm{~mm}$ de diâmetro foi acoplada no cilindro da máquina, transferindo assim o carregamento à face

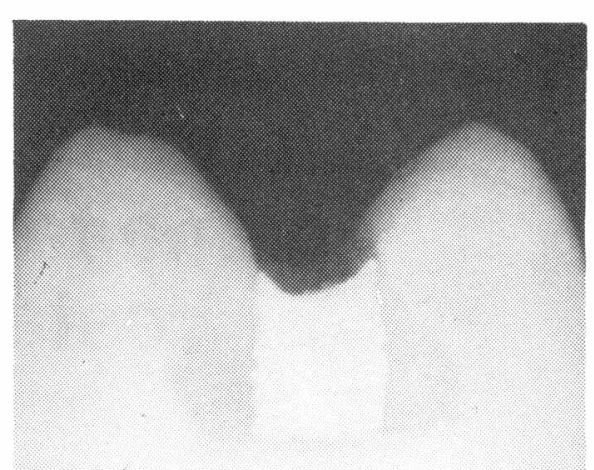

Secçāo vestíbulo-lingual do dente com Cermet suportando esmalte socavado associado a restauraçāo de amálgama

oclusal do dente. Um cilindro plástico impedia que fragmentos dos dentes, quando aplicada a força, se perdessem, permitindo assim a análise da manutenção do esmalte socavado (fig. 3). Os resultados de resistência à fratura obtidos foram então submetidos a análise estatística através do teste de Tukey ao nível de $5 \%$ de significância.

\section{Resultados}

$\mathrm{Na}$ execução dos testes de carregamento axial observou-se que no grupo 3, o cermet apresentou melhor desempenho com relaçăo a manutenção do esmalte socavado após a fratura dos dentes, comparativamente aos demais grupos teste (tabela 2).

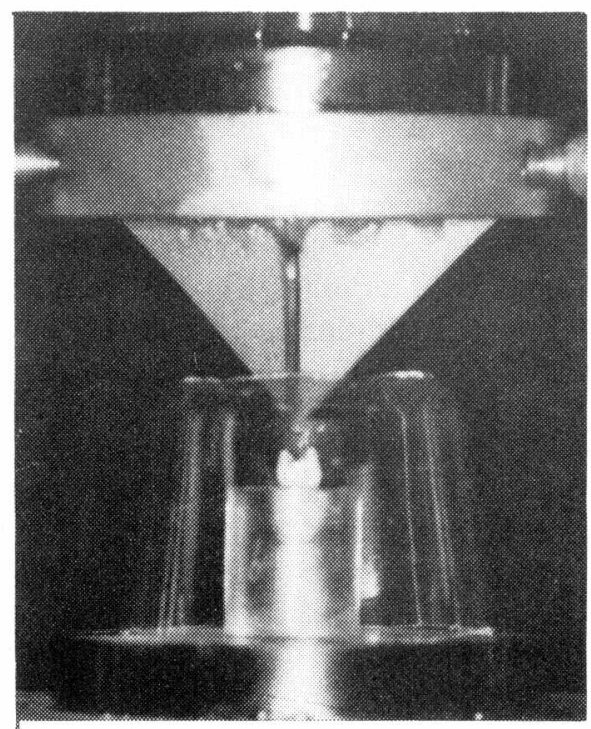

Dente submetido ao carregamento axial de compressão em uma máquina de ensaio universal (Losenhausenwerk) 
TABELA 2

Avaliaçāo de Fratura do Esmalte Socavado

\begin{tabular}{lc} 
Grupo & Fratura do Esmalte Socavado \\
\hline 1. Preparo não restaurado & $100 \%$ \\
2. Amálgama suportando esmalte & $100 \%$ \\
3. lonômero suportando esmalte & $42.8 \%$ \\
\hline
\end{tabular}

A tabela 3 mostra os valores médios da resistênciaà fratura e seus respectivos coeficientes de variaçăo.

TABELA 3

Resistência à Fratura (Kgf)

\begin{tabular}{lcccc}
\hline Grupo & No Rep. & Média & Coef. de Var. & $\mathbf{5 \%}$ \\
\hline 1. Prep. não rest. & 7 & 46.14 & 31.51 & A \\
2. Prep. + amálg. & 7 & 80.00 & 16.69 & B \\
3. Prep. + ion. amálg & 7 & 93.14 & 8.06 & B \\
\hline
\end{tabular}

Teste de Tukey - médias seguidas por letras distintas diferem entre si ao nível de $5 \%$ significância DMS $5 \%=15,012$

Os grupos 2 e 3 apresentaram maior resistência à fratura que o grupo 1 , controle, e estatisticamente valores similares entre si quanto à resistência à fratura.

\section{Conclusões}

1. O cermet apresentou melhor desempenho na manutenção do esmalte sem apoio de dentina quando submetido a força de compressão, comparado com as demais condiçōes experimentais.

2. A restauração dos dentes, grupos 2 e 3, aumentou a resistência à fratura destes em 2 vezes.

\section{Discussão}

O propósito da dentística atual com a utilizaçăo de materiais restauradores adesivos não é somente restabelecer a forma e a função do dente, mas manter a maior quantidade de tecido dentário hígido possibilitando a manutenção da integridade mecânica e biológica do dente restaurado.

O padrão de progressão de cárie nos dentes posteriores dá-se de maneira que a dentina é atingida em maior extensăo que o esmalte como mostra a fig. 4. Em funçăo disso quando confeccionamos preparos cavitários para amálgama faz-se obrigatoriamente uma remoção de tecido hígido, pois seguindo os princípios do preparo cavitário devemos remover todo esmalte sem suporte de dentina. No entanto, quando utiliza-se um material restaurador adesivo essa remoção de tecido dentário hígido não ocorre, pois o preparo cavitário limita-se a remoção de tecido cariado.

Trabalhos de DONLY, WILD e JENSEN 1988 (6) e JAGADISH e YOGE-

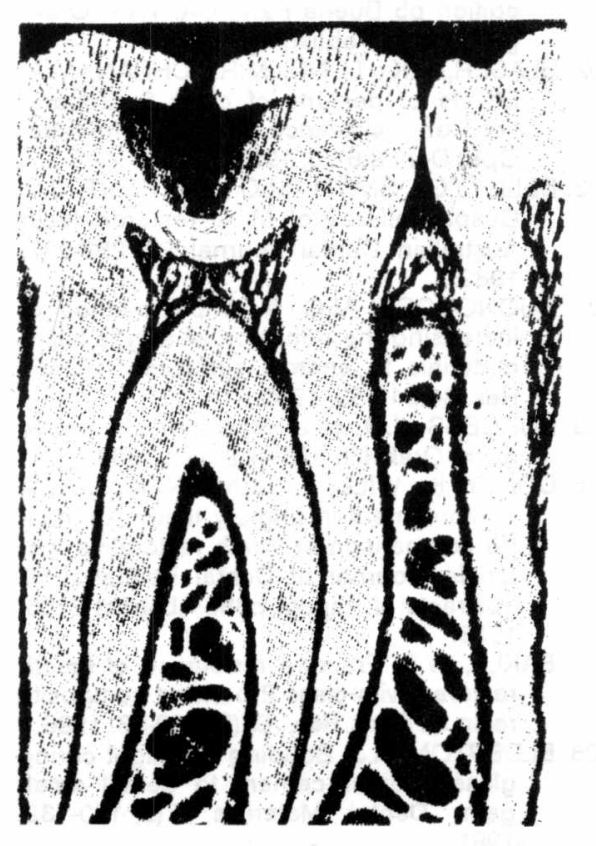

Lesảo oclusal se estende lateralmente ao longo da junçäo dentina-esmalte e em direçāo à polpa através da dentina. Adaptado de Legler DW, Menaker L. (15)
SH 1990 (13), demonstraram que o cimento de ionômero de vidro restaurador é melhor que o amálgama e inferior à resina composta no reforço da estrutura dentária em dentes posteriores. Contudo produz melhor resistência que os dentes intactos. É interessante notar que em nosso estudo o grupo restaurado com CERMET suportando esmalte socavado produziu melhor resistência à fratura que os dentes não restaurados e resultados estatisticamente similares ao amálgama (grupo 2) no aumento da resistência à fratura. Este resultado aparentemente controvertido pode ser devido ao fato do CERMET (grupo 3) estar somente suportando esmalte socavado e năo unindo as cúspides vestibular e palatina, e também devido ao preparo para o amálgama (grupo 2) neste estudo ter sido igual ao do CERMET (grupo 3), ou seja, não se removeu o esmalte socavado. Clinicamente, para confecção de uma restauração de amálgama seria exigido a remoção do esmalte socavado aumentando a extensão do preparo, diminuindo assim a resistência à fratura dos dentes restaurados $(2,3,25,29,30)$. Contudo - CERMET apresentou resultado bem superior ao amálgama na manutenção do esmalte socavado. No grupo do esmalte suportado por amálgama houve fratura do esmalte socavado em $100 \%$ dos casos, o que pode ser explicado pelo baixo módulo de elasticidade do amálgama $\left(6.9 \times 10_{4}\right)$ que não absorve as forças, desta maneira fraturando o esmalte sobreposto, que é consideravelmente friável. Este resultado vem a confirmar o princípio para o preparo cavitário onde se preconiza a remoção do esmalte, quando este for ser suportado por amálgama. No grupo 3 , CERMET, ocorreu fratura do esmalte socavado em apenas $42,8 \%$ dos dentes. Este resultado pode ser explicado pela adesão do CERMET às estruturas dentárias e as propriedades físicas que são aproximadas a da dentina (24).

O CERMET apresenta ainda características que reforçam sua indicação como material de suporte para o esmalte socavado associado ao amálgama como material restaurador. 0 
ionômero através da liberação de ions flúor é capaz de tornar o esmalte adjacente mais resistente à cárie (28). Além disso McCULLOCK e SMITH, 1986b demonstraram que o ionômero reduz significativamente a deflexão das cúspides quando comparado com a resina composta, pois a resina composta pode levar a formação de uma fenda entre o dente e o material restaurador, dor pós-operatória, microfraturas devido a flexão das cúspides e infiltração marginal especialmente na região cervical, devido a contração de polimerização $(16,19)$. Contudo, os testes com resina composta têm mostrado sua efetividade no aumento da resistência à fratura dos dentes (20). No entanto, foi demonstrado que este reforço pode diminuir com o tempo e com a termociclagem (7).

Idealmente então, a resina composta só deve ser utilizada quando houver esmalte em toda margem da cavidade e não houver contato cêntrico sobre a restauração. Portanto, os compósitos ainda năo alcançaram um estágio de desenvolvimento que os credenciem a ser empregados como substituto do amálgama.

Já por sua vez o CERMET suportando esmalte socavado atua de duas formas na manutenção da resistência do dente: diminui a quantidade de tecido dentário hígido a ser removido no preparo cavitário para amálgama, o que não sendo evitado levaria a redução da metade da cúspide tornando-a 8 vezes mais suscetível a deflexão $(12,17)$ e pela adesão à estrutura dentária que a reforça (18).

É importante notar que devido a metodologia aplicada se fez o carregamento oclusal de maneira contínua até que ocorresse a fratura do dente. Acreditamos que o resultado com o CERMET suportando esmalte sem apoio de dentina poderia ter sido ainda melhor se fosse possivel aplicar apenas forças dentro de um padrão fisiológico e de ciclo intermitente pois MALCON e HOOD 1977 (17) e GRINALDI e HOOD 1973 (12), BELL col. 1982 (3) DOUGLAS 1985 e MORIN e col. 1988 (26) em seus estudos de fratura de cúspides em dentes restaurados concluíram que a fratura de cúspide ocorre como resultado da fadiga da estrutura dentária que propaga microfraturas sob carregamentos repetidos. Por essa razão o uso de materiais restauradores adesivos foi considerado para a manutenção da resistência do dente restaurado.

As variaçōes individuais na morfologia entre os dentes, incluindo a idade do dente e respectivo volume pulpar, a angulação das cúspides, e a espessura do esmalte, foram os fatores que aparentemente contribuíram para o largo padrão de desvio dentro dos grupos.

O amálgama ainda é o material mais utilizado na região posterior em função de seu baixo custo, facilidade de manipulação e extensa avaliação clínica do seu desempenho. Entendemos, que a utilização do CERMET suportando esmalte socavado associado à restauração de amálgama constitui-se em um importante recurso para o clínico na preservação da integridade mecânica e biológica do dente restaurado. Isto porque combina as propriedades destes materiais restauradores resultando em economia de tempo e custo se compararmos com restauraçōes metálicas fundidas ou coroas totais. Contudo, investigaçōes clínicas serāo necessárias para comprovar a eficiência desta técnica restauradora.

\section{REFERÊNCIAS BIBLIOGRÁFICAS}

01. BASSETT, R.W.; INGRAHAM, R.; KOSER, J.R. An atlas of cast gold procedures $1 \mathrm{st}$ edition p5 Buena Park, CA: West Orange Country Publishing. 1964.

02. BLASER, P.K.; LUND, M.R.; CHRAN, M.A. Effects of designs of class 2 preparations on resisteance of tooth to fracture. Oper Dent 8:6-10, 1983.

03. BELL, J.G.; SMITH, M.C.; DE PONT, J.J. Cuspal failures of MOD restored teeth Australian Dental Journal 27 283-287, 1982.

04. BUONOCORE, M.G. A simple method of increasing the adhesion of acrylic filling materials to enamel surfaces. J. Dent. Res. 34:849-53, 1955.

05. BURGESS, J.O. et al. Posterior composite reisn. Oral Hith., 78(4):29-30, 1988

06. DONLY, K.; WILD, T.; JENSEN, M. Cuspal reinforcement in primary teeth: An in vitro comparison of threth restorative materials. Journal of Dental Research 67 abstracts of Papers p380 Abstract 2135, 1988.

07. EAKLE, W.S. Fracture resistance of theeth restored with class 2 bonded composite resin. J. Dent. Res., 65(2):149-53, 1986.

08. ELDERTON, R.J. Bonding of a light curing glass-ionomer cement to dental amalgam. Dental Materials. 7(2):130-132, 1991.

09. ELDERTON, R.J. The prevalence of failure of restorations: a literature review. J. Dent., 4(5):207-10, Sep. 1976.

10. GALAN, J.R., J. Contribuiçāo ao estudo das principais dimensōes de dentes humanos permanentes de leucodermas brasileiros em ambos os sexos. Revista Brasileira de Odontologia. 163:145-8, 1970.

11. GELB, M.N.; BAROUCH, E.; SIMONSEN, R.J. Resistance to cusp fracture in class 2 prepared and restored premolars. Journal of Prosthetic Dentistry. 55:184-85, 1986.

12. GRINALDI, J.R.; HOOD, J.A. Lateral deformation of the tooth crown under axial cuspal loading. J. Dent. Rest. 582-584, 1973.

13. JAGADISH, S.; YOGESH, B.G. Fracture resistance of teeth with class 2 silver amalgam, posterior composite, and Glass Cermet restorations. Operative Dentistry, 15, p.42-47, 1990.

14. LARSON, T.D.; DOUGLAS, W.H.; GEISTFELD, R.E. Effect of prepared cavities on the estrength of teeth. Oper. Dent. 6:2-5, 1981.

15. LEGLER, D.W.; MENAKER, L. Definiçāo, etiologia, epidemiologia e implicaçōes clínicas da cárie dentária. In: MENAKER, LEWIS et al. Cárie dentária; bases biológicas. Rio de Janeiro; Guanabara Koogan, 1984. Cap. 8 p.197.

16. LUE, J.L. Margin quality and microleakage of class 2 composite resin restorations. J. Amer. Dent. Ass. 114(1):49-54, 1987.

17. MALCON, P.J.; HOOD, J.A. The effect of cas restorations in reducing cusp flexibility in restored teeth. J. Dent. Res. 56d 200, 1977

18. MORIN, D.; DELONG, R.; DOUGLAS, W.H. Cusp reinforcement by acidetch technique Journal of Dental Research. 63:1075-1078, 1984.

19. MCCULLOCK, A.J.; SMITH, B.G.N. In vitro studies of cuspal movement produced by adhesive restorative materials. British Dental Journal. 161:405-409, 1986. A

20. McCULLOCK, A.J.; SMITH, B.G.N. In vitro studies of cuspal reinforcement with adhesive restorative material. Britsh Dental Journal. 161:450-452, 1986.B

21. McLEAN, J.W.; GASSER, O. Glass cermet cements. Quintessence int. 16:333-343, 1985.

22. McLEAN, J.W. et al. The use of glass-ionomer cements in bonding composite resins to dentine. Br. Dent. J. 158:410-414, 1985.

23. McLEAN, J.W. Glass ionomer cement. Br. Dent. J. 164(9) :293-300, 1988.

24. McLEAN, J.W. Estado actual y futuro del uso clinico de los cementos de ionomero vitreo. RADA - Vol. 79 n.3 - Julio/Septiembre p. 157-164, 1991.

25. MONDELLI, et al. Fracture strenght of human with cavity preparations. J. Prosth Dent. 43:419-422, 1980.

26. MORIN, D.; DOUGLAS, W.H.; CROSS, M.; DELONG, R. Biophysical stress analysis of restored teeth: experimental strain measurement. Dent. Maer. 4:41-48, 1988.

27. MORIN, D.; DeLONGR; DOUGLAS, W.H. Cusp reinforement by the acidetch technique. J. Dent. Res. 63(8):1075-1078, 1984.

28. WILSON, A.D.; PROSSER, H.J. A survey of inorganic and polyelectyrolite cements. Brit. Dent. J. 157:44-54, 1984.

29. VALE, W.A. Cavity preparation, Irish Dent. Rev. 2:33-41, 1956.

30. VALE, W.A. Cavity preparation and further thougts high speed, Br. Dent. J. 107:333-346, 1959.
R. Fac. Odontol.

Porto Alegre

V. 33

N. 1

p.5-8

JULHO

1992 